\title{
Erratum to: No evidence for shared representations of task sets in joint task switching
}

\author{
Motonori Yamaguchi $^{1}$ ([) $\cdot$ Helen J. Wall ${ }^{1} \cdot$ Bernhard Hommel $^{2}$
}

Published online: 21 November 2016

(c) Springer-Verlag Berlin Heidelberg 2016

\section{Erratum to: Psychological Research}

\section{DOI 10.1007/s00426-016-0813-y}

The original version of this article unfortunately contained a mistake. The presentation of Fig. 1 was incorrect. The corrected figure is given below.

The online version of the original article can be found under doi:10.1007/s00426-016-0813-y.

Motonori Yamaguchi

yamagucm@edgehill.ac.uk

1 Department of Psychology, Edge Hill University, St Helens Road, Ormskirk, Lancashire L39 4QP, UK

2 Institute of Psychology, Leiden University, Leiden, The Netherlands 
Fig. 1 Mean response times (RT) and percentages of error trials (PE) for the joint condition (a) and the individual condition (b) as a function of task sequence and the previous trial in Experiment 1 (error bars represent one standard error of the mean)

\section{A Joint Condition}
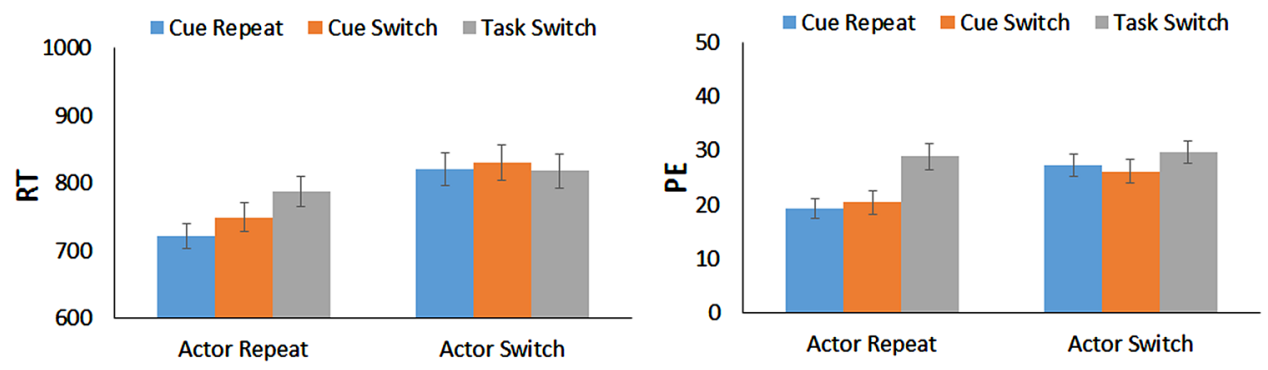

\section{B Individual Condition}
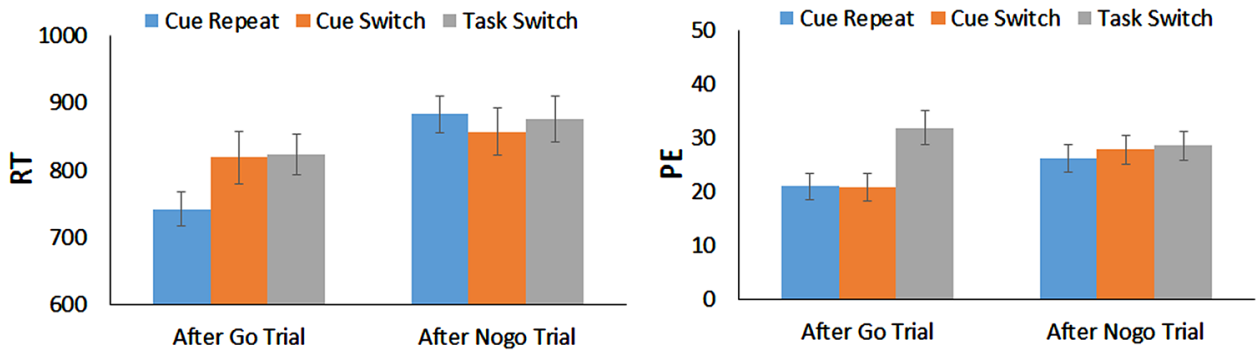